Revista Universo Contábil, ISSN 1809-3337
Blumenau, v. 14, n. 2, p. 07-29, abr.jun., 2018
doi:10.4270/ruc.2018209
Disponível em www.furb.br/universocontabil

\title{
INCERTEZA E INVESTIMENTO: UMA ABORDAGEM SOB A ÓTICA DA TEORIA DAS OPÇÕES REAIS ${ }^{1}$
}

\section{UNCERTAINTY AND INVESTMENT: AN APPROACH FROM REAL OPTIONS THEORY FRAMEWORK}

\section{INCERTIDUMBRE Y INVERSIÓN: UN ENFOQUE SOBRE LA PERSPECTIVA DE LA TEORÍA LAS OPCIONES REALES}

\author{
POLYANDRA ZAMPIERE PESSOA DA SILVA \\ Mestre em Ciências Contábeis pelo Programa Multiinstitucional e Inter-Regional de \\ Pós-Graduação em Ciências Contábeis - UnB/UFPB/UFRN \\ Professora de Ciências Contábeis do Instituto de Educação Superior da Paraíba \\ Endereço: Rua: Getúlio Vargas, 01, Centro \\ CEP: 58278-000 - Jacaraú - PB - Brasil \\ E-mail:polyandra@live.com \\ Telefone: (83) 98829-1857
}

\begin{abstract}
MÁRCIO ANDRÉ VERAS MACHADO
Doutor em Administração pela Universidade de Brasília Professor do Programa de Pós-Graduação em Administração da Universidade Federal da Paraíba e do Programa Multiinstitucional de Pós-Graduação em Ciências Contábeis - UnB/UFPB/UFRN. Endereço: Cidade Universitária - Campus I, Castelo Branco CEP: 58059-900 - João Pessoa - PB - Brasil E-mail: mavmachado@hotmail.com Telefone: (83) 3216-7482
\end{abstract}

\section{RESUMO}

Este trabalho teve por objetivo analisar o efeito da incerteza sobre o nível de investimento das empresas do mercado brasileiro. A amostra foi composta por todas as empresas não financeiras listadas na B3 entre o período de 2008 a 2014. Como proxy para a incerteza total, utilizou-se a volatilidade histórica do retorno das ações. Decompôs-se essa medida em três componentes de risco: o de mercado, o idiossincrático e o específico da firma. Além disso, utilizou-se uma proxy alternativa para medição da incerteza, a volatilidade condicional do retorno das ações. Para análise do efeito da incerteza sobre as decisões de investimento, utilizou-se o método de Mínimos Quadrados Ordinários (MQO) e Mínimos Quadrados em Dois Estágios (MQ2E). Os resultados indicam que a incerteza total tem um efeito negativo sobre o nível de investimento, conforme esperado. Quanto às incertezas de mercado e idiossincrática, verificou-se que não há um efeito estatisticamente significativo sobre o nível de investimento, enquanto que a incerteza

\footnotetext{
${ }^{1}$ Artigo recebido em 28/01/2017. Revisado por pares em 25/11/2018. Reformulado em 06/12/2018. Recomendado para publicação em 17/12/2018 por Tarcísio Pedro da Silva. Publicado em 20/02/2019. Organização responsável pelo periódico: FURB.
} 
INCERTEZA E INVESTIMENTO: UMA ABORDAGEM SOB A ÓTICA DA TEORIA DAS OPÇÕES REAIS

específica tem um efeito negativo e significativo, inclusive superior em magnitude ao da incerteza total. Ademais, identificou-se que, para o mercado brasileiro: i) as empresas com restrição financeira e as mais competitivas são mais sensíveis às proxies de incerteza; ii) que os resultados são robustos para o período de full IFRS; e iii) que não houve alteração significativa nos resultados encontrados ao utilizar uma medida alternativa para a variável incerteza. Portanto, pode-se concluir que a incerteza tem um efeito negativo sobre o nível de investimento, com destaque para a incerteza específica da firma, que possui um efeito superior, quando comparado às demais incertezas. Sendo assim, o estudo espera contribuir trazendo o debate do uso de modelos alternativos para análise de investimento que considerem a incerteza e a flexibilibilidade gerencial do ambiente de negócios, fatores que são relevantes para avaliação de projetos.

Palavras-chave: investimento, incerteza, Teoria das Opções Reais.

\section{ABSTRACT}

This research aimed to analyze the effect of uncertainty on the level of investment by companies in the Brazilian market. The sample consisted of all non-financial companies listed on the B3 between 2008 and 2014. As a proxy for the total uncertainty, we used the historical volatility of stock returns. This measure was decomposed into three risk components: market, idiosyncratic and specific to the firm. In addition, we used an alternative proxy to measurement the uncertainty, the conditional volatility of the stock return. To analyze the effect of uncertainty on investment decisions, we used the method of Ordinary Least Squares (OLS) and Two-Stage Least Squares (2SLS). The results indicate that the total uncertainty has a negative effect on the level of investment, as expected. Regarding the market and idiosyncratic uncertainties, we found there is no statistically significant effect on the level of investment, whereas the specific uncertainty has a significant negative effect, even higher in magnitude than the total uncertainty. Furthermore, we found that, in Brazilian market: i) companies with financial constraints and most competitive are more sensitive to uncertainties; ii) the results are robust for the full IFRS period; and iii) there was no significant change in the results found for the use of an alternative measure for uncertainty. Thus, we can conclude that an uncertainty has a negative effect on the level of investment, especially for a specific company that has a superior effect when compared to the other uncertainties. Therefore, the study hopes to contribute by bringing the debate to the use of alternative models of investment analysis that consider the uncertainty and managerial flexibility of the business environment, which are relevant for project evaluation.

KEYWORDS: Investment; Uncertainty; Real Options Theory.

\section{RESUMEN}

Este trabajo tuvo por objetivo analizar el efecto de la incertidumbre sobre el nivel de inversión de las empresas en el mercado brasileño. La muestra fue compuesta por todas las empresas no financieras en lista en BM\&FBovespa en el período de 2008 a 2014. Como proxy para la incertidumbre total, fue utilizada la volatilidad histórica del retorno de las acciones. La incertidumbre fue decompuesta en tres componentes de riesgo: el de mercado, el idiosincrático y el específico de cada empresa. Además, se utilizó una proxy alternativa para medir la incertidumbre, la volatilidad condicional de la acción. Para analizar el efecto de incertidumbre en las decisiones de inversión, se utilizó el método de mínimos cuadrados ordinarios (MQO) y mínimos cuadrados en dos etapas (MQ2E). Los resultados indican que la incertidumbre total tiene un efecto negativo en el nivel de inversión, como se esperaba. En cuanto a las incertidumbres del mercado y idiosincrático, se encontró que existe un efecto estadísticamente significativo sobre el nivel de inversión, mientras que la incertidumbre específica tiene un efecto negativo y significativo, incluso mayor en magnitud que la incertidumbre total. Además, 
Polyandra Zampiere Pessoa da Silva - Márcio André Veras Machado

se constató que, en el mercado brasileño: i) las empresas con restricción financiera y más competitivas son más sensibles a la incertidumbre;; ii) que los resultados son robustos al período de full IFRS; y iii) que no hubo cambios significativos en los resultados encontrados al utilizar una medida alternativa a la incertidumbre. Por lo tanto, se pude concluir que la incertidumbre tiene un efecto negativo en el nivel de inversión, con énfasis en la incertidumbre de la empresa que tiene un mayor efecto en comparación con otras incertidumbres. Por lo tanto, el estudio espera contribuir con el debate del uso de modelos alternativos de análisis de inversión que consideren la incertidumbre y la flexibilización gerencial del ambiente de negocios, que son relevantes para la evaluación de proyectos.

Palabras-clave: Inversión; Incertidumbre; Teoría de las Opciones Reales

\section{INTRODUÇÃO}

As constantes mudanças do ambiente empresarial, devido ao crescimento acelerado das economias, e as inovações tecnológicas promoveram um aumento da competição e da incerteza no espaço corporativo, tornando a flexibilidade gerencial essencial para o processo de tomada de decisão dos administradores (XU; WANG; XIN, 2010).

Conforme Trigeorgis (1996) e Minardi (2000), a flexibilidade gerencial refere-se ao fato de que, com o passar do tempo, os investidores podem alterar suas decisões de investimento, à medida que obtêm novas informações sobre o projeto, visando à maximização dos retornos e à redução das perdas. Adicionalmente, Dixit e Pindick (1994) e Bekoe e Adom (2013) afirmam que, em um ambiente de incerteza, as decisões de investimento devem levar em consideração a interação entre três características: (a) irreversibilidade parcial ou completa; (b) incerteza quanto aos retornos gerados pelo projeto; e (c) timming quanto ao momento ideal da decisão do investimento (flexibilidade gerencial).

No entanto, os métodos tradicionais de análise de investimento reais negligenciam a interação dessas três características, considerando que os investimentos são do tipo "agora ou nunca" e que os gestores se utilizam de estratégias passivas para administração dos seus projetos (MINARDI, 2000; BEKOE; ADOM, 2013). Assim, dentre os inúmeros métodos que foram criados para resolver as falhas dos modelos tradicionais, destaca-se a Teoria das Opções Reais (TOR) como o mais promissor (DIXIT; PINDYCK, 1994; MINARDI, 2000; BULAN, 2005).

A TOR é uma metodologia de análise de investimentos reais, análoga às opções de compra do mercado financeiro, que permite ao administrador valorar as diversas opções existentes em qualquer projeto de investimento - como as de adiar, contrair, abandonar ou efetuar qualquer alteração no projeto, nos diversos estágios por ele assumidos, dentro do seu período de duração (TRIGEORGIS, 1996).

Nessa ótica, diversos autores (DIXIT; PINDYCK, 1994; TRIGEORGIS, 1996; BULAN, 2001, 2005; BULAN; MAYER; SOMERVILLE, 2009; TRAN, 2014) têm defendido a utilização da TOR para análise de investimentos, uma vez que, devido à irreversibilidade, à incerteza e ao timming (flexibilidade gerencial), a capacidade de adiar um investimento tornase valiosa, tendo em vista que o investidor poderá aguardar a redução da incerteza antes de decidir fazer o investimento irreversível, a fim de evitar potencializar grandes perdas, renunciando ao investimento completamente quando o resultado for desfavorável.

Dessa forma, tem-se que, quanto maior for à incerteza em relação aos fluxos de caixa futuros esperados de um investimento, mais valiosa é a opção de adiar o projeto, reduzindo o incentivo para o exercício da opção hoje. Sendo assim, pode-se afirmar que a incerteza tem efeito negativo sobre o volume de investimento das empresas (BULAN, 2005; BULAN; MAYER; SOMERVILLE, 2009; XU; WANG; XIN, 2010; TRAN, 2014).

Entretanto, a TOR não é o único modelo a prever essa relação negativa entre incerteza e investimento. A teoria tradicional afirma que essa relação também pode ser explicada pelo 
INCERTEZA E INVESTIMENTO: UMA ABORDAGEM SOB A ÓTICA DA TEORIA DAS OPÇÕES REAIS

risco sistemático (calculado pelo Capital Asset Pricing Model (CAPM), por exemplo), uma vez que afeta o custo de capital das empresas, aplicado nos modelos tradicionais de fluxo de caixa descontado (FCD) para análise de investimento (BULAN, 2005; BULAN; MAYER; SOMERVILLE, 2009). Uma taxa de desconto de capital mais alta resulta em um menor valor presente líquido (VPL) dos projetos de investimento e, portanto, menos investimentos serão feitos (BULAN, 2005; PANOUSI; PAPANIKOLAOU, 2012).

As pesquisas empíricas têm se esforçado para diferenciar o efeito da TOR e da teoria tradicional (modelos tradicionais de FCD em que a taxa de desconto depende do risco) nas decisões de investimento, uma vez que ambas defendem um efeito negativo da incerteza sobre o investimento (BULAN; MAYER; SOMERVILLE, 2009). Entretanto, Bulan (2001, 2005) e Bulan, Mayer e Somerville (2009) endossam que, diferentemente do risco sistemático (mercado), que está para reduzir o investimento em uma variedade de modelos, inclusive na TOR, o risco da indústria e específico da firma sobre o investimento é exclusivo para o modelo de opções reais, distinguindo, portanto, o comportamento das opções reais dos modelos tradicionais.

Ressalta-se que, para a TOR, é a incerteza total, isto é, a de mercado, a idiossincrática e a específica da firma, que importa para as decisões de investimento, enquanto que, para a teoria tradicional, o único risco relevante para a empresa é o de mercado, uma vez que as empresas possuem investimentos diversificados. Logo, o risco não sistemático não deve ter efeito sobre a valorização de um projeto (BULAN, 2001, 2005). Neste trabalho, os termos risco e incerteza são considerados idênticos, uma vez que a literatura sobre opções reais refere-se à volatilidade da demanda variável subjacente, tal como uma medida de incerteza (BULAN, 2001).

Nesse sentido, realizaram-se inúmeros estudos, nacional e internacionalmente (BULAN, 2005; BLOOM; BOND; REENEN, 2007; BAUM; CAGLAYAN; TALAVERA, 2008, 2010; XU; WANG; XIN, 2010; PANOUSI; PAPANIKOLAOU, 2012; TRAN, 2014), visando verificar o efeito da incerteza sobre o nível/volume de investimentos. A maioria deles evidenciou um efeito negativo da incerteza sobre o volume de investimento, contudo, poucos demonstraram se essa evidência era devido ao comportamento das opções reais ou de teorias alternativas. Especificamente, na literatura nacional, não foi identificado nenhum estudo que buscasse justificar seus resultados, partindo da ótica das opções reais.

Além disso, a maioria dos estudos a respeito do efeito da incerteza sobre o nível de investimento foi desenvolvido no Reino Unido e Estados Unidos da América (EUA), e poucos autores têm se dedicado a pesquisar em países não anglo-saxônicos (SÂMAN, 2010; BEKOE; ADOM; 2013; TRAN, 2014). Contudo, Tran (2014) endossa que é necessário o desenvolvimento de pesquisas nessa área em outros países, uma vez que podem ser encontrados resultados diferentes que irão auxiliar o entendimento sobre a temática. Assim, tem-se a seguinte questão de pesquisa: Qual o efeito da incerteza sobre o nível de investimento das empresas do mercado brasileiro? Portanto, o objetivo é analisar o efeito da incerteza sobre o nível de investimento das empresas do mercado brasileiro. A compreensão do efeito da incerteza sobre o volume de investimento das organizações é de suma importância para a tomada de decisões de investimento (BULAN, 2005; TRAN, 2014), principalmente quando os países estão passando por um período de crise na economia nacional, uma vez que eleva a incerteza quanto ao futuro dos projetos (ESCALARES; KOTTARIDI, 2014). Ressalta-se que o Brasil, país escolhido para a análise do estudo, durante o período da pesquisa (2008 a 2014), é marcado por uma fase de pós crise do subprime e prenúncio da recessão econômica brasileira, que teve início no segundo trimestre de 2014, com uma redução gradual das taxas de crescimento do Produto Interno Bruto (PIB) do país (BORÇA JUNIOR; TORRES FILHO, 2008; BARBOSA FILHO, 2017).

Quanto ao desenvolvimento de pesquisas na temática estudada, nos últimos anos, três temáticas têm sido abordadas em estudos sobre o comportamento das decisões de investimento 
Polyandra Zampiere Pessoa da Silva - Márcio André Veras Machado

das empresas (XU; WANG; XIN, 2010): (a) investimento e restrições financeiras; (b) investimento e sensibilidade às dívidas; e (c) relação entre incerteza e investimento com base na TOR. As duas primeiras temáticas são bem documentadas na literatura, enquanto que o efeito da incerteza sobre o nível de investimento com base na TOR ainda é pouco documentada e apresenta resultados conflitantes (XU; WANG; XIN, 2010; BULAN, 2005). Aliadas a isso, somam-se as diferentes proxies para mensuração da incerteza, nos períodos estudados, assim como diversos métodos econométricos, que dificultam a comparação de resultados.

Desse modo, a presente pesquisa contribuirá, ao trazer o debate do efeito da incerteza sobre o nível de investimento sob a ótica das opções reais, sobretudo com dados de mercados emergentes. Assim, os resultados encontrados poderão fomentar o estabelecimento de novas políticas corporativas que levem em consideração outros tipos de risco na avaliação de investimento. Adicionalmente, espera-se que, partindo dos resultados do presente estudo, os administradores e os demais usuários da informação possam alocar seus recursos de maneira mais eficiente, visando à maximização de sua riqueza.

\section{ESTUDOS ANTERIORES E HIPÓTESE DE PESQUISA}

A literatura a respeito das decisões de investimentos tem evidenciado uma grande preocupação em relação ao efeito da incerteza no comportamento dos investimentos das empresas, principalmente na identificação de uma proxy de incerteza que afete o nível de investimento (BULAN, 2005). Nesse sentido, esta seção apresenta um resumo das principais pesquisas que estudaram o comportamento dos investimentos em condições de incerteza e que fundamentaram as hipóteses da presente pesquisa.

Sob a ótica da TOR, Bulan (2005) investigou o efeito da incerteza total no comportamento dos investimentos. Para tanto, utilizou como medida para incerteza total a volatilidade do retorno das ações, que foi decomposta em seus componentes de mercado, indústria e específicos da firma. Os resultados evidenciaram que o investimento tem uma relação negativa com as incertezas idiossincrática e específica da firma, consistente com as opções reais, enquanto que a relação com a incerteza sistemática é positiva. Os achados são robustos para segregações na amostra que consideram irreversibilidade do capital, concorrência e tamanho da empresa.

Assim como Bulan (2005), Bloom, Bond e Reenen (2007) utilizaram como proxy para incerteza a volatilidade do retorno das ações, visando analisar a dinâmica do comportamento do investimento em condições de incerteza. Os autores constataram que, com (parcial) irreversibilidade, elevados níveis de incerteza tendem a diminuir os níveis de investimento das empresas, uma vez que aumentam a opção real de adiar o investimento.

Utilizando-se de três medidas de incerteza: (a) própria (intrínseca), derivada do retorno das ações das empresas; (b) do mercado (extrínseca), impulsionada pelo retorno do índice S\&P500; e (c) relação entre incerteza intrínseca e extrínseca, Baum, Caglayan e Talavera (2008), investigaram o impacto das proxies de incerteza sobre o comportamento dos investimentos de capital.Os resultados indicaram que a incerteza da firma, medida pela volatilidade do retorno diário das ações, assim como a incerteza baseada na medida de risco do CAPM, tem um impacto negativo nas despesas de investimento; enquanto que a incerteza do mercado, medida pelo índice do mercado de capitais (o índice S\&P 500), tem um efeito positivo, sugerindo que, a relação entre investimento e incerteza é sensível à proxy utilizada ou que os gestores utilizam-se de métodos diferentes para prever a incerteza.

Posteriormente, Baum, Caglayan e Talavera (2010), utilizando a mesma base de dados e proxies para incerteza do seu trabalho de 2008, investigaram a relação entre as decisões de investimento com o fluxo de caixa em condições de incerteza. Os resultados indicaram que o sinal do coeficiente de incerteza é negativo para a: incerteza específica da firma, incerteza de 
mercado (o índice S\&P 500) e incerteza baseada na medida de risco do CAPM. Contudo, quando a incerteza foi associada ao fluxo de caixa, os resultados foram ambíguos.

Seguindo a metodologia do estudo de Bulan (2005), Xu, Wang e Xin (2010) identificaram que, para as empresas chinesas de controle privado, a relação entre investimento e incerteza é negativa, enquanto que, para as controladas pelo governo, o efeito é positivo, demonstrando que, além da proxy utilizada para medir incerteza, o tipo de controle também pode influenciar o efeito da incerteza sobre o comportamento de investimento. Os autores justificam tais resultados, endossando que as empresas controladas pelo governo tendem a aumentar seu nível de investimento em período de maior incerteza para estimular o crescimento econômico. Ratificando o exposto, Bloom, Bond e Reenen (2007) identificaram que as empresas privadas são menos sensíveis a estímulos monetários e fiscais em períodos de elevada incerteza. Sendo assim, para estimular o crescimento, o governo poderia interferir via organizações com controle estatal.

Com um enfoque na aversão ao risco gerencial, Panousi e Papanikolaou (2012) analisaram o efeito da incerteza idiossincrática no nível de investimentos das empresas. Para tanto, utilizaram como medida de referência para a incerteza a volatilidade mensal do retorno das ações, que foi decomposta em componentes sistemáticos e críticos. Assim, demonstraram que há uma relação negativa robusta, e provavelmente causal, entre o risco idiossincrático e o investimento para as empresas de capital aberto dos Estados Unidos da América (EUA). Contudo, a relação negativa é mais forte, quando os executivos possuem uma carteira de investimento pouco diversificada e grande fração de ações da empresa, tendo em vista a aversão ao risco. Ressalta-se que o comportamento entre empresas privadas e de capital aberto no processo de tomada de decisão de investimento podem ser semelhantes, uma vez que as decisões são tomadas por executivos poucos diversificados e não por acionistas bem diversificados. Nesse sentido, observa-se que o grau de aversão ao risco empresarial é significativo para as de decisões de investimento.

Corroborando o estudo de Bulan (2005) e Xu, Wang e Xin (2010), Tran (2014) identificou que a incerteza especifica da firma é mais importante para as decisões de investimento do que a incerteza macroeconômica, conforme prevê a TOR. Além disso, o autor destaca que: i) a magnitude do efeito da incerteza é relativamente mais forte sobre o nível de investimento em comparação com as demais variáveis do estudo, Q de tobin, fluxo de caixa, alavancagem e receita de vendas; e ii) as empresas menores são mais sensíveis as mudanças no ambiente de negócios (incerteza), possivelmente por sofrerem maior assimetria informacional, pelas restrições financeiras e de acesso ao mercado de capitais externo.

Assim, diante dessas evidências empíricas, pode-se concluir que existe um efeito negativo da incerteza sobre o nível de investimento, isto é, que um aumento da incerteza reduz o nível de investimento das empresas. Duas abordagens norteiam a explicação dessa relação negativa: a teoria tradicional e a TOR (BULAN, 2001, 2005; BULAN; MAYER; SOMERVILLE, 2009). A teoria tradicional defende que os administradores deixam de investir, quando houver um aumento no risco sistemático, tendo em vista que eleva o custo de capital da empresa, aumentando, assim, a taxa de desconto utilizada para avaliar o VPL dos novos projetos de investimentos. Esse aumento na taxa de desconto resulta em menores VPL's dos projetos e, portanto, menos investimentos serão realizados, uma vez que a empresa terá menos capital disponível para novos investimentos (BULAN; MAYER; SOMERVILLE, 2009).

Partindo dessa abordagem tradicional, existe uma série de evidências do efeito da incerteza de mercado sobre o nível de investimento. Tran (2014), por exemplo, identificou que, para o mercado australiano, o efeito do risco sistemático é negativo e significante estatisticamente. Resultados semelhantes foram encontrados por Baum, Caglayan e Talavera (2008), para o mercado norte-americano. Assim, baseando-se na teoria tradicional e nos estudos 
Polyandra Zampiere Pessoa da Silva - Márcio André Veras Machado

de Baum, Caglayan e Talavera (2008) e Tran (2014), estabelece-se a primeira hipótese de pesquisa:

$\mathrm{H}_{1}$ - As empresas reduzem o nível de investimento em períodos de alta incerteza de mercado.

Quanto à segunda abordagem, a TOR defende que a relação entre incerteza e investimento é negativa, tendo em vista que os investidores têm a opção de adiar um investimento, diante de um elevado nível de incerteza, a fim de capturar mais informações a respeito do investimento antes de concretizá-lo (BULAN, 2005). De acordo com Bulan (2001, 2005) e Tran (2014), a opção de adiar um investimento é relevante, uma vez que a maioria das despesas de capital das firmas é irreversível (ou parcialmente irreversível), ou seja, o preço de capital de compra é inferior ao seu preço de revenda.

Destaca-se que, para teoria tradicional, apenas o risco sistemático (a incerteza de mercado) é relevante para as organizações, enquanto que, para TOR, não só o risco de mercado tem influência sobre o nível de investimento, mas sim o risco total (risco de mercado, risco idiossincrático e especifico da firma). Nesse sentido, baseando-se na TOR e nas evidências de Bulan (2005) e Xu, Wang e Xin (2010), que encontraram um efeito negativo da incerteza total sobre o nível de investimento, tem-se a segunda hipótese de pesquisa:

$\mathrm{H}_{2}$ - As empresas reduzem o nível de investimento em períodos de alta incerteza total.

Contudo, para verificar se o efeito da incerteza sobre o nível de investimento é, de fato, justificada pela TOR, faz-se necessária a decomposição da incerteza total em seus componentes de risco de mercado, idiossincrático e específico da firma. Assim, caso seja observado que as incertezas idiossincráticas ou específicas da firma tenham um efeito negativo e significativo sobre o nível de investimento, poder-se-á concluir que o efeito é causado pela TOR. Do contrário, haverá uma ambiguidade quanto à abordagem que explica a relação negativa entre a incerteza e o nível de investimento das organizações, uma vez que tanto a teoria tradicional, quanto a TOR, defendem que a incerteza de mercado tem impacto no nível de investimento.

Portanto, conforme o exposto e partindo dos estudos de Bulan (2005) e Xu, Wang e Xin (2010), que analisaram o efeito das incertezas idiossincrática e específica da firma sobre o nível de investimento das empresas norte-americanas e chinesas, respectivamente, têm-se as seguintes hipóteses:

$\mathrm{H}_{2 \mathrm{a}}$ - As empresas reduzem o nível de investimento em períodos de alta incerteza idiossincrática;

$\mathrm{H}_{2 b}$ - As empresas reduzem o nível de investimento em períodos de alta incerteza especifica da firma.

\section{PROCEDIMENTOS METODOLÓGICOS}

Esta pesquisa caracteriza-se como empírico-analítica, uma vez que se utiliza de técnicas de coleta, tratamento e análise de dados de cunho quantitativo; descritivo-explicativa, em virtude da apresentação dos dados e por buscar descrever e explicar as possíveis relações entre as variáveis, incerteza e investimento, com base na teoria; e de abordagem quantitativa, em função da coleta de informações, assim como do uso de recursos e de técnicas estatísticas no tratamento dos dados. A seguir evidencia-se o percurso metodológico, especificamente a amostra do estudo, a mensuração da incerteza e o modelo econométrico. 


\subsection{Amostra do estudo}

A amostra inicial analisada foi constituída por todas as empresas com ações listadas na Brasil, Bolsa, Balcão (B3), entre o período de $1^{\circ}$ de janeiro de 2008 a 31 de dezembro de 2014. Esse marco temporal foi escolhido por causa da disponibilidade de informações dos índices setoriais a partir do ano de 2008.

Da referida amostra, foram excluídas as seguintes empresas: a) financeiras e de seguro, devido a seu relativamente baixo nível de investimento em capital físico (TRAN, 2014), assim como devido ao seu alto grau de alavancagem que pode distorcer os resultados da pesquisa (FAMA; FRENCH, 1992); b) as que não apresentaram valor de mercado no dia 31 de dezembro de cada ano, pois esses valores são utilizados para computar o $q$ de Tobin; c) as que tiverem menos de 125 observações de retorno durante o ano, restringindo a amostra a empresas que comercializam por, pelo menos, $50 \%$ dos pregões em um ano; e d) que não apresentaram os dados necessários para a pesquisa. Todos os dados relativos a informações contábeis e de mercado foram obtidos por meio do banco de dados do Economatica ${ }^{\circledR}$ e do sítio eletrônico da B3.

\subsection{MENSURAÇÃO DA INCERTEZA}

De acordo com Bulan (2001, 2005) e Bekoe e Adom (2013), a obtenção de uma medida geral de incerteza que afeta as empresas não é uma tarefa simples. Na literatura, vários tipos de proxies têm sido utilizadas para medir a incerteza, tais como: fluxo de caixa, preço da ação, inflação, retorno das ações, dentre outras (BULAN, 2005; BLOOM; BOND; REENEN, 2007; BAUM; CAGLAYAN; TALAVERA, 2008, 2010; XU; WANG, XIN, 2010; TRAN, 2014).

Para este estudo, utilizou-se a volatilidade dos retornos das ações, uma vez que apresenta a vantagem de capturar, em uma única variável, a incerteza total que é relevante para empresa, facilitando a decomposição do risco em seus vários componentes (BULAN, 2001, 2005). Além disso, de acordo com Bulan (2005), Baum, Caglayan e Talavera (2008, 2010), Xu, Wang e Xin, (2010) e Tran (2014), a volatilidade dos retornos das ações é uma medida adequada, pois reflete os fatores de incerteza macros e microeconômicos enfrentados pelas organizações, capturando as reações do mercado quanto às notícias de oportunidades de investimento e rentabilidade futura que são relevantes para as decisões de investimentos das empresas.

Sendo assim, a volatilidade do retorno das ações, ou seja, o desvio padrão dos retornos diários da empresa, foi calculado conforme Equação 1:

$$
\sigma_{i \tau}=\sqrt{\frac{1}{t_{i}} \sum_{\tau=1}^{t_{i}}\left(r_{i \tau}-\bar{r}_{i t}\right)^{2}}
$$

Em que: $\sigma_{i \tau}=$ desvio padrão do retorno diários da ação $i$ no dia $\tau ; \tau=1,2, \ldots, \mathrm{t}_{\mathrm{i}} \cdot \mathrm{t}_{\mathrm{i}}$ é o número de dias de negociação no ano $t ; r_{i \tau}=$ retorno diário da empresa $i$ no dia $\tau$; e $\bar{r}_{i t}=\mathrm{a}$ média do retorno diário da empresa $i$ no ano $t$. Os retornos diários são utilizados porque geram medidas de volatilidade anual sem sobreposição de dados de retorno e minimizam o viés de pequena amostra (BULAN, 2005).

Para verificar se a TOR explica a relação negativa entre investimento e incerteza, a incerteza total foi decomposta em seus componentes agregados e específicos da firma. Para tanto, foi utilizado o modelo de dois índices apresentado na Equação 2, com base nos estudos de Bulan $(2001,2005)$ e Xu, Wang e Xin (2010).

$$
R_{i \tau}=\alpha_{i t}+\beta_{i t} R_{M \tau}+\gamma_{i t} R_{I \tau}+\varepsilon_{i \tau}
$$


Em que: $R_{i \tau}=$ é o retorno diário das ações da empresa $i$ no dia $\tau ; \tau=1,2, \ldots, t i$ e $t i$ são os números de dias de negociação da empresa $i$ no ano $t ; \alpha_{i t}=$ intercepto da regressão; $\beta_{i t}=$ é o beta da incerteza de mercado da empresa $i$ no ano $t ; R_{M \tau}=$ retorno diário da carteira índice de mercado-IBovespa; $\gamma_{i t}=$ gama da incerteza do setor da empresa $i$ no ano $t ; R_{I \tau}=$ retorno diário da carteira índice do setor da empresa, que é ortogonal ao retorno do mercado; e $\varepsilon_{i \tau}=$ o termo de erro com ruído branco.

O modelo acima foi estimado, utilizando MQO para cada empresa, em cada ano da amostra do estudo. Nesse sentido, a incerteza do mercado foi mensurada pelo beta de mercado das empresas multiplicado pelo desvio padrão anualizado do retorno da carteira do índice de mercado $\left(\widehat{\beta}_{\mathrm{it}} \cdot \widehat{\sigma}_{\mathrm{Mt}}\right)$. Similarmente, a incerteza idiossincrática, que é ortogonal com o movimento da incerteza do mercado, foi mensurada pelo gama do setor da empresa multiplicado pelo desvio padrão anualizado do retorno da carteira índice do setor $\left(\hat{\gamma}_{i t} \cdot \widehat{\sigma}_{\text {It }}\right)$.

Quanto à incerteza específica da empresa $\left(\widehat{\sigma}_{\varepsilon i \tau}\right)$, foi mensurada pelo desvio padrão anualizado dos resíduos resultantes da regressão da Equação 2. É importante ressaltar que a volatilidade anual do retorno do mercado $\left(\hat{\sigma}_{M t}\right)$ e a volatilidade do retorno da indústria $\left(\hat{\sigma}_{I t}\right)$ são ortogonais ao retorno total do mercado $\left(\hat{\sigma}_{i t}\right)$. Além disso, destaca-se que todas as medidas de volatilidade foram multiplicadas pela raiz quadrada de 252 (número de dias de negociação em um ano), com o objetivo de anualizá-las.

Para efeito de comparação, uma medida alternativa de decomposição da incerteza total é estimada com a restrição que $\gamma_{i t}=0$ na Equação 2, cenário análogo ao CAPM. De acordo com Bulan (2001, 2005), nesse modelo alternativo, a incerteza agregada está relacionada inteiramente com as forças do mercado, enquanto que a incerteza específica da empresa é resultado do componente de retorno que é ortogonal a apenas os movimentos de mercado.

Comparando-se os dois modelos, tem se que, no modelo de dois índices (Equação 2), os efeitos diretos do índice de mercado e do índice da indústria no retorno das ações das firmas são medidos por parâmetros separados, enquanto que no modelo de mercado (análogo ao CAPM) o efeito do índice da indústria está intrínseco no índice de mercado, isto é, o beta de mercado captura o efeito indireto do índice da indústria no retorno do patrimônio da empresa, uma vez que é canalizado por meio do índice de mercado.

É importante destacar que toda medição da incerteza tem que ser voltada para o futuro, tendo em vista que deve refletir rentabilidade futura. As medidas tratadas nesta pesquisa são $e x$ post. Contudo, sob a hipótese de expectativas racionais, pode-se usar valores de volatilidade defasados como proxy para volatilidade esperada (BULAN, 2005).

Ressalta-se, ainda, que a proxy utilizada para medir a incerteza do mercado, neste estudo, é comumente referida na literatura de finanças como risco sistemático, uma vez que a volatilidade dos retornos de ativos é uma medida de grau de risco do ativo. Entretanto, a literatura de opções reais refere-se à volatilidade da demanda variável subjacente, tal como uma medida de incerteza. Nesse sentido, o risco e as incertezas podem ser considerados sinônimos (BULAN, 2001).

Por fim, informa-se que foi necessário calcular o retorno diário dos setores de Petróleo, Tecnologia e Telecomunicações, uma vez que tal informação não estava disponível no site da BM\&FBovespa. Para tanto, seguiu-se parcialmente a metodologia utilizada pela BM\&FBovespa para os demais setores. Esse procedimento foi realizado, tendo em vista que o retorno diário dos setores representa uma variável necessária para decomposição da incerteza total, conforme Equação 2. 


\subsection{Descrição do modelo econométrico}

O modelo adotado nesta pesquisa teve como base os trabalhos de Bulan (2005), Baum, Caglayan e Talavera (2008, 2010), Xu, Wang e Xin (2010) e Tran (2014). Assim, para mensurar o efeito da incerteza sobre o nível de investimento, utilizou-se a Equação 3:

$$
\begin{aligned}
\frac{I_{i t}}{K_{i t-1}}=\beta_{0}+ & \beta_{1} Q T \text { obin }_{i t-1}+\beta_{2} R G I_{i t-1}+\beta_{3} R M C_{i t-1}+\beta_{4} E N D_{i t-1}+\beta_{5} I N C_{-} T_{i t} \dashv \\
& +n_{i}+\xi_{t i}
\end{aligned}
$$

Em que: a variável dependente do modelo será $\frac{I_{i t}}{K_{i t-1}} ; I_{i t}$ é o nível/volume de investimento (as despesas de capital em propriedades, instalações e equipamentos, excluindo aquisições) da empresa $i$ no ano $t$; e $K_{i t-1}$ é o estoque de capital (imobilizado) da empresa $i$ no tempo $t$ - 1 .

As variáveis independentes são: $Q$ Tobin $_{i t-1}=q$ de Tobin para empresa $i$ no ano $t-1$; $R G I_{i t}=$ recursos gerados internamente para empresa $i$ no ano $t-1 ; R M C_{i t-1}=$ rentabilidade marginal do capital para empresa $i$ no tempo $t-1 ; E N D_{i t-1}=$ nível de alavancagem da empresa $i$ no tempo $t-1 ; I N C_{-} T_{i t}=$ incerteza total, que é mensurada por diversas medidas, conforme subseção 3.2; $v_{i}=$ dummy de setor, inserida na equação para controlar os efeitos fixos específicos de cada empresa em determinado setor; e $n_{i}=d u m m y$ de ano das empresas, inserida na estimação com objetivo de controlar efeitos macroeconômicos, como choques agregados que podem afetar as decisões de investimento das organizações. $\xi_{i t}=$ representa os resíduos da equação; e $\beta_{1}, \beta_{2}, \beta_{3}, \beta_{4}$ e $\beta_{5}=$ parâmetros do modelo.

Espera-se que $\beta_{1}$ seja significativamente positivo, tendo em vista que, quanto maior a oportunidade de investimento ( $q$ marginal), maior o estímulo para investir. Na Teoria do $q$ de Tobin, tem-se que o investimento deve ser uma função crescente da razão entre o valor de mercado da empresa e o custo de recompra de novos ativos fixos no mercado, que é capaz de indicar como novos investimentos afetarão o valor presente dos lucros das organizações. Essa razão é denominada de $q$ marginal, que representa a taxa de investimento da organização, ou seja, o $q$ marginal indica quanto, a cada unidade de valor investido, a empresa criará ou destruirá de valor (TOBIN, 1969).

Conforme Hayashi (1982), a relevância do $q$ está em mostrar a relação entre o valor investido e quanto o investimento passou a valer após ter sido transformado em bens e atividades produtivas. Assim, quando $q>1$, o mercado estará valorizando mais o capital do que o custo de reposição. Portanto, tem-se estímulo a investir. Entretanto, se $q<1$, a relação será inversa e o estímulo será inibido. Nesse sentido, o $q$ de Tobin representa a oportunidade de investimento da organização.

Quanto ao $\beta_{2}$, espera-se que tenha um sinal positivo, uma vez que quanto maiores os recursos gerados internamente, maiores serão os recursos para novos investimentos. A Pecking Order Theory (POT) aborda que há uma hierarquia de financiamento nas organizações, na qual primeiramente as empresas se financiam por recursos próprios, em seguida por recursos de terceiros e, em último caso, emitem novas ações (MYERS, 1984). Nesse sentido, devido aos problemas de agência e às restrições financeiras, o nível de investimento da organização pode estar totalmente relacionado aos recursos gerados internamente. Portanto, quanto mais recursos gerados internamente, maior o nível de investimento das organizações.

De acordo com Bulan (2005), o excesso de recursos gerados internamente pode pressionar os administradores a investirem em qualquer projeto que tenha um VPL positivo. Nessa ótica, as empresas gerarão maiores recursos internos e, consequentemente, tendem a investir cada vez mais para não perderem oportunidades de investimentos futuros. Nesse 
Polyandra Zampiere Pessoa da Silva - Márcio André Veras Machado

sentido, fez-se necessário capturar a rentabilidade marginal de capital e espera-se uma relação positiva $\left(\beta_{3}\right)$, tendo em vista que quanto maior a rentabilidade, maior deverá ser o investimento.

Em relação a $\beta_{4}$, espera-se um sinal significativamente negativo, uma vez que o excesso de dívida poderá inibir as oportunidades de captar recursos para investimento. Modigliani e Miller (1958) defendem que a estrutura de capital das organizações deveria ser irrelevante para a tomada de decisão. No entanto, conforme Myers (1984), as empresas mais alavancadas apresentam conflito de interesse entre os detentores de capital e os de dívida, o que provoca uma relação negativa entre os investimentos e a alavancagem, tendo em vista que os conflitos impedem que os gestores aceitem projetos que tenham VPL positivo na presença de altos níveis de endividamento.

Quanto ao parâmetro $\beta_{5}$, de acordo com a TOR, espera-se um sinal significativamente negativo, tendo em vista que quanto maior a incerteza, maior a opção de adiar um investimento e, consequentemente, menor será o nível de investimento das organizações. Resumidamente, no Tabela 1, tem-se as fórmulas utilizadas para o cálculo das variáveis explicativas, assim como o sinal esperado.

Tabela 1 - Resumo das Variáveis Explicativas e Sinal Esperado

\begin{tabular}{c|c|c|c}
\hline Variáveis & Sigla & $\begin{array}{c}\text { Sinal } \\
\text { Esperado }\end{array}$ & Fórmulas \\
\hline $\begin{array}{c}\text { Oportunidade de crescimento } \\
\begin{array}{c}\text { Recursos gerados } \\
\text { internamente }\end{array}\end{array}$ & QTobin & $(+)$ & $Q T o b i n_{i t}=\frac{V M A_{i t}+V P T_{i t}-A C_{i t}}{V A T_{i t}}$ \\
\hline $\begin{array}{c}\text { Rentabilidade marginal do } \\
\text { capital }\end{array}$ & RGI & $(+)$ & $R G I_{i t}=\frac{L L_{i t}+D E P R E_{i t}+A M O R T_{i t}}{K_{i t-1}}$ \\
\hline Nível de alavancagem & END & $(+)$ & $R M C_{i t}=\frac{R O B_{i t}}{K_{i t-1}}$ \\
\hline
\end{tabular}

Nota: VMA = valor de mercado das ações ordinárias e preferências da empresa; VPT = valor do passivo total; AC = ativo circulante; VAT = ativo total; $\mathrm{LL}=$ lucro líquido; DEPRE = depreciação; AMORT = amortização; K = imobilizado; $\mathrm{ROB}$ = receita operacional bruta; e $\mathrm{PT}=$ passivo total.

Destaca-se que, conforme a subseção 3.2, a incerteza total da empresa foi mensurada por diversas proxies, assim, para a estimação da Equação 3, as medidas de incerteza foram agrupadas em três modelos, conforme o estudo de Bulan (2005) e Xu, Wang e Xin (2010). No modelo (a), usa-se a volatilidade do retorno total das ações como medida para incerteza total (INC_Total) da empresa, enquanto o modelo (b) decompõe a incerteza total em seus componentes de mercado (INC_Merc(b)) e específico da firma (INC_Esp(b)), conforme a restrição $\gamma_{i t}=0$ imposta na Equação 2. O modelo (c) decompõe a incerteza total em três componentes: o de mercado (INC_Merc(c)), o da indústria (INC_Setor(c)) e o específico da firma(INC_Esp(c)), conforme o modelo de dois índices da Equação 2.

Em relação ao método econométrico para este trabalho, optou-se por utilizar a técnica de dados em painel. Assim, para identificar o tipo de dados em painel mais adequado às observações, fez-se necessário a aplicação de três testes, a saber: (a) teste de Chow; (b) teste Lagrange Multiplie (LM) de Breush-Pagan; e (c) teste de Hauman. Desta forma, foi possível verificar que o modelo mais adequado para a pesquisa é o painel do tipo pooled.

No que concerne à definição do método para estimação dos parâmetros da Equação 3, verificou-se, inicialmente, se as medidas de incerteza utilizadas no estudo eram endógenas, uma vez que Bulan (2005) destacou que poderia haver uma possível endogeneidade para essas medidas. Assim, fez-se necessário a aplicação do teste de Durbin, teste F e o teste de 
INCERTEZA E INVESTIMENTO: UMA ABORDAGEM SOB A ÓTICA DA TEORIA DAS OPÇÕES REAIS

Wooldridge, para os modelos (a), (b) e (c), no período de 2008 a 2014, bem como de full IFRS. Os instrumentos utilizados foram o $q$ de Tobin defasado e as demais medidas de incerteza, conforme o estudo de Bulan (2005) e Xu, Wang e Xin (2010).

A análise foi feita para os dois períodos, 2008 a 2014 e de full IFRS, em virtude da adoção da International Financial Reporting Standards (IFRS) pelas empresas brasileiras, que alteraram as políticas contábeis do país, especificamente a forma de reconhecimento, mensuração e evidenciação dos elementos contábeis. Sendo assim, por serem utilizados dados contábeis neste estudo, fez-se necessário a analise particular desse marco temporal. Nesse sentido, verificou-se que, nos três modelos analisados e para ambos os períodos, as variáveis são exógenas. Portanto, para estimar os parâmetros da Equação 3, para os três modelos ((a), (b) e (c)) e para ambos os períodos, foi utilizado o método de MQO com dados em painel não balanceado.

\section{ANÁLISE DOS DADOS}

\subsection{Estatística descritiva}

Nesta seção, apresenta-se a estatística descritiva, com o objetivo de demonstrar o comportamento do conjunto de variáveis da amostra do estudo que é composta por uma média de aproximadamente 186 empresas por ano, totalizando 1.278 observações. Assim, quanto à variável dependente do modelo, nível/volume de investimento, tem-se que, em média, as organizações aumentaram seu nível de investimento em aproximadamente 0,309 no período de 2008 a 2014, com um desvio padrão de 1,938. Esses valores corroboram o estudo de Sâmam (2010), que analisou dados da Romênia no período de 2000 a 2008. Contudo, divergem dos estudos com empresas norte-americanas, como os de Bulan (2005) e Baum, Caglayan e Talavera $(2008,2010)$, que obtiveram resultados inferiores para o nível de investimento. Essa diferença pode ser justificada pelas particularidades do mercado de capitais e economia de cada país e/ou pelas mudanças na mensuração de dados contábeis no período analisado.

Quanto às proxies para incerteza, tem-se que a INC_Total apresentou uma média de 0,531 e desvio padrão de 0,505, corroborando a pesquisa de Bulan (2005), para empresas norteamericanas, e a de Xu, Wang e Xin (2010), para empresas chinesas. Contudo, contrariou os estudos de Baum, Caglayan e Talavera $(2008,2010)$, para empresas norte-americanas, que apresentou resultados superiores $(0,849$, em média). Tal discrepância entre os estudos com empresas norte-americanas pode ser justificada pelos períodos em que o estudo foi realizado. Contudo, destaca-se que, em média, os países possuem um nível de incerteza do ambiente de negócios que são bem semelhantes. Esperava-se que o Brasil apresentasse um nível de incerteza total superior, considerando ser um país com um mercado de capitais incipiente.

No que concerne às variáveis de INC_Merc (b) e INC_Esp (b), calculadas com base na restrição $\gamma_{i t}=0$ na Equação 2, observou-se uma média de 0,150 e 0,467, com um desvio em torno da média de 0,154 e 0,305, respectivamente. Esses resultados corroboram o estudo de Bulan (2005). Em relação aos regressores, INC_Merc (c), INC_Setor (c) e INC_Esp (c), calculado pelo modelo de dois índices, observou-se que a média foi de 0,054, 0,120 e 0,455, respectivamente, sendo a INC_Esp (c) a que apresentou maior dispersão em torno da média (0,3030), condizente com os estudos de Bulan (2005) e de Xu, Wang e Xin (2010). Observa-se que, em ambas as proxies para a decomposição da incerteza, a INC_Esp apresentou valores superiores às de mercado e setor.Quanto às demais variáveis, QTobin, RGI, RMC e END, verificou-se que possuem média e desvio padrão alto, quando comparadas às demais variáveis da pesquisa, fato que pode ser justificado pelas características das empresas brasileiras com papéis negociados na B3 e/ou pela presença de observações com valores aberrantes (possivelmente causados pelas mudanças dos padrões contábeis a partir de 2010/full IFRS). 
Polyandra Zampiere Pessoa da Silva - Márcio André Veras Machado

\subsection{Incerteza e investimento}

Nesta seção, são apresentados os resultados do efeito da incerteza sobre o nível de investimento das organizações para o período de 2008-2014 e Full IFRS, com diferentes proxies para incerteza, conforme explicado na seção de procedimentos metodológicos. Ademais, foram realizados alguns testes de robustez, segregando as empresas por tamanho (proxy para restrição financeira e assimetria informacional), competitividade, bem como a utilização de uma medida alternativa de incerteza.

Dessa forma, conforme Tabela 2, observa-se que, para o período de 2008 a 2014, a incerteza total teve um efeito negativo e significativo sobre nível de investimento das empresas, isto é, um aumento de $1 \%$ na incerteza total da empresa diminui o nível de investimento em 0,2567\%, conforme o modelo (a). Esses resultados são condizentes com a TOR, que defende que, em elevados níveis de incerteza, a opção de adiar um investimento é valiosa, e corroboram os achados de Bulan (2005), Baum, Caglayan e Talavera $(2008,2010)$, para o mercado norteamericano, os de Bloom, Bond e Reenen (2007), para o mercado do Reino Unido, os de Xu, Wang e Xin (2010), para o mercado chinês, e os de Tran (2014), para o mercado australiano.

Tabela 2 - Efeito da incerteza sobre o nível de investimento para o período de 2008-2014 e Full IFRS.

\begin{tabular}{|c|c|c|c|c|c|c|}
\hline \multirow{2}{*}{ Variáveis } & \multicolumn{3}{|c|}{ 2008-2014 } & \multicolumn{3}{|c|}{ Full IFRS } \\
\hline & $(a)^{1}$ & $(b)^{1}$ & $(c)^{1}$ & (a) ${ }^{1}$ & $(b)^{1}$ & $(c)^{1}$ \\
\hline QTobin & $0,0005^{* * *}$ & $0,0005^{* * *}$ & $0,0005^{* * *}$ & $0,0006^{* * *}$ & $0,0006^{* * *}$ & $0,0006^{* * *}$ \\
\hline RGI & $-0,0002 * * *$ & $-0,0002 * * *$ & $-0,0002 * * *$ & $-0,0002 * * *$ & $-0,0002 * * *$ & $-0,0002 * * *$ \\
\hline RMC & $0,0006^{* * *}$ & $0,0007 * * *$ & $0,0007 * * *$ & $0,0008^{* * *}$ & $0,0006^{* *}$ & $0,0008 * * *$ \\
\hline END & $0,0447 * *$ & $0,0451 * * *$ & $0,0450 * * *$ & $0,0691 * * *$ & $0,0691 * * *$ & $0,0691 * * *$ \\
\hline INC_Total & $-0,2567 * * *$ & - & - & $-0,2161^{* *}$ & - & - \\
\hline INC_Mer & - & 0,6090 & 0,3911 & - & $2,9983^{*}$ & 0,5159 \\
\hline INC_Setor & - & - & 0,1202 & - & - & $-0,0181$ \\
\hline INC_Esp & - & $-0,4706 * * *$ & $-0,4328 * * *$ & - & $-0,3506^{*}$ & $-0,3636^{* *}$ \\
\hline Intercepto & $1,0479 * * *$ & $1,0822 * * *$ & $1,0915^{* * *}$ & $1,0328 * * *$ & $0,7829 * * *$ & $1,0726^{* * *}$ \\
\hline $\mathbf{R}^{2}$ & 0,3570 & 0,3593 & 0,3576 & 0,5371 & 0,5498 & 0,5371 \\
\hline Teste F & 23,33 & 25,51 & 22,80 & 23,77 & 24,18 & 22,78 \\
\hline (p-valor) & 0,0000 & 0,0000 & 0,0000 & 0,0000 & 0,0000 & 0,0000 \\
\hline T. Jarque-Bera & 0,0000 & 0,0000 & 0,0000 & 0,0000 & 0,0000 & 0,0000 \\
\hline T. White & 0,0000 & 0,0000 & 0,0000 & 0,0000 & 0,0000 & 0,0000 \\
\hline T. Wooldridge & 0,0000 & 0,0000 & 0,0000 & 0,0000 & 0,0000 & 0,0000 \\
\hline Observações & 1.278 & 1.278 & 1.278 & 942 & 942 & 942 \\
\hline
\end{tabular}

Nota: (1) Erros padrão estimados com correção para heterocedasticidade e correlação serial, usando Newey-West com 1 lag, uma vez que a hipótese nula de variância homocedastica foi rejeitada, ao nível de 1\%, assim como de autocorrelação serial para todos os modelos; $\left({ }^{2}\right)$ em nenhum dos modelos foi encontrada multicolinearidade verificada por meio do teste VIF; $\left({ }^{3}\right)$ a hipótese nula do teste de Jarque-Bera foi rejeitada, contudo, baseando no teorema do limite central e considerando que foram utilizadas 1.278 e 942 observações, o pressuposto foi relaxado (BROOKS, 2008); $\left(^{5}\right)$ foram usadas dummies para setor e ano em todos os modelos, visando controlar o efeito fixo do ano e setor na amostra do estudo; $\left({ }^{6}\right) * * *$ significante ao nível de $1 \%$; ** significante ao nível de 5\%; * significante ao nível de $10 \%$.

Especificamente, $\mathrm{Xu}$, Wang e Xin (2010) evidenciaram que um aumento de $1 \%$ na incerteza total para as empresas chinesas diminuía o investimento em $0,155 \%$, enquanto Bulan (2005) verificou que um aumento de $1 \%$ na incerteza total reduzia o nível de investimento em $0,4732 \%$. Assim, observa-se, de acordo com os estudos analisados, que a incerteza total tem um maior impacto sobre o nível de investimento das empresas norte-americanas, em relação às empresas chinesas e brasileiras. 
Destaca-se que, durante os anos de análise do estudo (2008 a 2014), a economia brasileira estava passando por um período de pós crise do subprime e de anti-recessão econômica (BORÇA JUNIOR; TORRES FILHO, 2008; BARBOSA FILHO, 2017). Esses fatores podem ter impactado no nível de incerteza total do mercado de capitais, assim como de todo o mundo.

No modelo (b), tem-se que a incerteza de mercado obteve um coeficiente positivo e não significativo sobre o nível de investimento, contrariando o efeito esperado, tendo em vista que, segundo a teoria tradicional, a incerteza de mercado deveria afetar negativamente o nível de investimento, por meio da taxa de desconto (custo de capital). Contudo, diversos outros estudos analisados neste trabalho encontraram resultados semelhantes. Bulan (2005) e Baum, Caglayan e Talavera (2008), por exemplo, analisando empresas norte-americanas, verificaram um efeito positivo e significativo da incerteza de mercado sobre o investimento, enquanto $\mathrm{Xu}$, Wang e Xin (2010) não encontraram um efeito significativo da incerteza de mercado sobre o nível de investimento das empresas chinesas.

Quanto à incerteza específica, com base na restrição $\gamma_{i t}=0$ imposta na Equação 2, modelo (b), observa-se que apresentou um coeficiente negativo e significativo sobre o nível de investimento, inclusive com um efeito superior ao da incerteza total, uma vez que o aumento de $1 \%$ na incerteza específica reduz o nível de investimento em $0,4796 \%$. Esse resultado é consistente com a TOR, que defende que a incerteza específica tem efeito negativo sobre o investimento, devido ao capital específico da firma ser irreversível. Os estudos de Bulan (2005), Xu, Wang e Xin (2010) e Tran (2014) apresentaram resultados semelhantes, inclusive quanto à intensidade do efeito da incerteza específica, quando comparado à da incerteza total.

No modelo (c), percebe-se que apenas a incerteza específica da firma apresentou um efeito negativo e significativo sobre os investimentos, isto é, um aumento de $1 \%$ na incerteza reduz o investimento em 0,4328 ; os demais componentes de riscos apresentaram um efeito positivo e não significativo, corroborando os achados de Xu, Wang e Xin (2010), para o mercado chinês, e contrariando os achados de Tran (2014), para o mercado australiano. Contudo, ressalta-se que esses resultados corroboram parcialmente os achados de Bulan (2005), para o mercado norte-americano, no período de 1966-1999, uma vez que, em seu estudo, apenas as incertezas da indústria e específica da firma apresentaram um efeito negativo e significativo.

Resumidamente, com base nos três modelos ((a), (b) e (c)) e para o período de 2008 a 2014, é possível verificar que a incerteza total tem um efeito negativo e significativo sobre o nível de investimento, corroborando os achados de Bulan (2005), para empresas norteamericanas, Bloom, Bond e Reenen (2007), para as empresas do Reino Unido, Xu, Wang e Xin (2010), para empresas chinesas, e Tran (2014), para o mercado australiano. No entanto, quanto às demais medidas de incerteza, apenas a incerteza específica apresentou um efeito negativo e significativo, conforme o estudo de Xu, Wang e Xin (2010), no mercado chinês. Esse último resultado confirma que o efeito negativo da incerteza que importa para o nível de investimento é o especifico da firma, condizente com o previsto pela TOR.

Nesse sentido, ressalta-se que as empresas brasileiras precisam levar em consideração a incerteza especifica no processo de tomada de decisão, tendo em vista a magnitude do impacto dessa variável no nível de investimento das firmas, principalmente se comparar com a magnitude das demais variáveis do estudo. Infelizmente, os modelos tradicionais de análise de investimento não consideram essa particularidade na análise de investimento, portanto, métodos alternativos devem ser levados em consideração, tais como a TOR, com a finalidade melhorar as políticas de investimentos das empresas.

Quanto às variáveis explicativas $q$ de Tobin, recursos gerados internamente (RGI), rentabilidade marginal de capital (RMC) e endividamento (END), observa-se que, para todos os modelos analisados, obtiveram coeficientes muito similares e significantes estatisticamente. Porém, as variáveis RGI e END apresentaram sinal contrário ao esperado. Esse fato pode ser 
Polyandra Zampiere Pessoa da Silva - Márcio André Veras Machado

justificado pelas particularidades da economia brasileira. Especificamente, os recursos gerados internamente deveriam ter um efeito positivo sobre o nível de investimento, tendo em vista que, de acordo com a POT, as empresas inicialmente se financiam por recursos próprios, no entanto, devido aos benefícios fiscais brasileiros para a capitação de recursos de terceiros, esse resultado pode ser inverso ao esperado. Além disso, as organizações brasileiras podem ter uma política rigorosa de dividendos, logo, dando preferência pelo pagamento de dividendos em detrimento ao financiamento por recursos próprios.

Em relação à variável endividamento, esperava-se um efeito negativo, uma vez que as empresas mais alavancadas apresentam conflito de interesse entre os detentores de capital e os de dívida, fazendo com que os gestores evitem projetos com VPL positivo em altos níveis de endividamento. No entanto, devido ao benefício fiscal e um menor custo de capital, as empresas podem optar por aumentar o seu endividamento na realização de novos investimentos, o que justificaria o coeficiente positivo da estimação. Além disso, no Brasil, uma das principais fontes para crescimento do ativo é o financiamento (MACHADO, FAFF, 2018).

No que concerne ao período de full IFRS, pode-se constatar, no modelo (a), que a incerteza total apresentou um efeito negativo e significativo sobre o nível de investimento, conforme esperado. Quanto ao modelo (b), observa-se que a incerteza de mercado teve um efeito positivo e significativo sobre o investimento, enquanto que a incerteza específica obteve um efeito negativo e significativo. Esses resultados corroboram o estudo de Bulan (2005) e Baum, Caglayan e Talavera (2008), para o mercado norte-americano, apesar de ser esperado um efeito negativo e significativo para incerteza de mercado. Destaca-se que, para o período de 2008 a 2014, o efeito da incerteza de mercado não foi estatisticamente significativo.

No que concerne ao modelo (c), verifica-se que os resultados foram compatíveis com o do período de 2008 a 2014, apresentando apenas a incerteza específica da firma como significativa estatisticamente e com um efeito negativo sobre o nível de investimento. Quanto às demais variáveis explicativas, os resultados também foram muito semelhantes ao do período de 2008 a 2014, inclusive para as variáveis que não apresentaram o sinal esperado (RGI e END). Nesse sentido, verifica-se que, com exceção da variável INC_Mer do modelo (b), os demais resultados obtidos foram semelhantes para o marco temporal de 2008 a 2014. Portanto, tem-se que os resultados são robustos para o período pós Full IFRS. Por fim, destaca-se que o coeficiente de determinação $\left(\mathrm{R}^{2}\right)$ para os modelos estimados no período de 2008 a 2014 apresentaram um poder explicativo médio de 0,3579 , enquanto que para o período de full IFRS foi de 0,5413 , indicando que $35 \%$ e $54 \%$, respectivamente, das variações do nível de investimento, são explicadas pelas variações das variáveis independentes.

\subsection{Tamanho da empresa}

Nesta subseção, explorou-se o efeito do tamanho da empresa sobre a relação entre incerteza e investimento, conforme os estudos de Bulan (2005), Panousi e Papanikolaou (2012), Czarnitzki e Toole (2013) e Tran (2014). Para Panousi e Papanikolaou (2012) e Tran (2014), o tamanho da empresa representa uma proxy para restrição financeira e assimetria informacional entre o credor e devedor. Dessa forma, espera-se que as empresas mais restritas (menores empresas) tenham um maior impacto da incerteza sobre o nível de investimento do que as empresas irrestritas (maiores empresas).

Como proxy para tamanho da empresa, utilizou-se o logaritmo natural do ativo total (LNAT), conforme Bulan (2005) e Tran (2014). Nesse sentido, as empresas foram agrupadas com base na mediana do LNAT, isto é, empresas com LNAT $\geq$ mediana foram classificadas como firmas maiores, e os demais casos como firmas menores. A Tabela 3 apresenta os resultados da estimativa da Equação 3, com diferentes proxies para incerteza, para as firmas maiores e as menores. 
Assim, conforme Tabela 3, percebe-se que, para o grupo com as firmas maiores, a incerteza total, modelo (a), não teve um efeito significativo estatisticamente sobre o nível de investimento, corroborando o estudo de Tran (2014), para empresas australianas, e contrariando os achados de Bulan (2005), para empresas norte-americanas. Quanto ao modelo (b), constatase que as incertezas de mercado e a específica também não apresentaram efeito significativo sobre o investimento. Bulan (2005) obteve resultados parecidos, um efeito não significativo para a incerteza de mercado e um efeito negativo e significativo para a incerteza específica. No que concerne ao modelo (c), constata-se que a incerteza específica tem um efeito negativo e significativo sobre o investimento, corroborando os achados de Bulan (2005). Em relação ao $\mathrm{R}^{2}$, observa-se um poder explicativo médio de 0,1515 , inferior ao do modelo com todas as empresas do estudo.

Tabela 3 - Efeito da incerteza sobre o investimento para firmas maiores e menores (2008-2014).

\begin{tabular}{|c|c|c|c|c|c|c|}
\hline \multirow{2}{*}{ VARIÁVEIS } & \multicolumn{3}{|c|}{ Firmas Maiores } & \multicolumn{3}{|c|}{ Firmas Menores } \\
\hline & $(\mathbf{a})^{2}$ & $(\mathbf{b})^{2}$ & $(c)^{2}$ & $(\mathbf{a})^{1}$ & $(b)^{1}$ & $(c)^{1}$ \\
\hline QTobin & $-0,0002$ & 0,0000 & $-0,0003$ & $0,0005 * * *$ & $0,0005 * * *$ & $0,0005^{* * *}$ \\
\hline RGI & 0,0319 & 0,0306 & 0,0314 & $-0,0002 * * *$ & $-0,0002 * * *$ & $-0,0002 * * *$ \\
\hline RMC & $-0,0008$ & $-0,0010$ & $-0,0010$ & $0,0007 * * *$ & $0,0007 * * *$ & $0,0007 * * *$ \\
\hline END & $-0,8977 * *$ & $-1,0927 * *$ & $-1,1137$ & $0,0447 * * *$ & $0,0450 * * *$ & $0,0452 * *$ \\
\hline INC_Total & 0,004 & - & - & $-0,3261 * *$ & - & - \\
\hline INC_Mer & - & 1,6290 & 0,7438 & - & 0,0752 & $-0,5314$ \\
\hline INC_Setor & - & - & 0,8165 & - & - & $-0,3839$ \\
\hline INC_Esp & - & 0,3437 & $0,5882 *$ & - & $-0,4548 * *$ & $-0,4122 * *$ \\
\hline Intercepto & $1,5422 * * *$ & $1,3180 * * *$ & $1,3355 * * *$ & $1,0621 * * *$ & $1,1306 * * *$ & $1,1475 * * *$ \\
\hline $\mathbf{R}^{2}$ & 0,1464 & 0,1556 & 0,1526 & 0,5851 & 0,5861 & 0,5862 \\
\hline Teste F & 2,66 & 2,52 & 2,43 & 187,00 & 195,08 & 175,43 \\
\hline (p-valor) & 0,0000 & 0,0000 & 0,0000 & 0,0000 & 0,0000 & 0,0000 \\
\hline T. Jarque-Bera & 0,0000 & 0,0000 & 0,0000 & 0,0000 & 0,0000 & 0,0000 \\
\hline T. White & 0,0000 & 0,0000 & 0,0000 & 0,0000 & 0,0000 & 0,0000 \\
\hline T. Wooldridge & 0,7360 & 0,8270 & 0,7686 & 0,0240 & 0,0250 & 0,0090 \\
\hline Observações & 640 & 640 & 640 & 638 & 638 & 638 \\
\hline
\end{tabular}

Nota: ${ }^{1}$ ) Erros padrão estimados com correção para heterocedasticidade e correlação serial, usando Newey-West com 1 lag, uma vez que a hipótese nula de variância homocedastica foi rejeitada, ao nível de 1\%, assim como de autocorrelação serial para todos os modelos; ( $\left.{ }^{2}\right)$ Erros padrão estimados com correção para heterocedasticidade, usando Huber-White, tendo em vista que a hipótese nula de variância homocedastica foi rejeitada ao nível de $1 \%$; $\left(^{3}\right)$ em nenhum modelo foi encontrada multicolinearidade verificada por meio do teste VIF; $\left({ }^{4}\right)$ a hipótese nula do teste de Jarque-Bera foi rejeitada, contudo, baseando no teorema do limite central e considerando que foram utilizadas 640 e 638 observações, o pressuposto foi relaxado (BROOKS, 2008). $\left({ }^{5}\right)$ foram usadas dummies para setor e ano em todos os modelos, visando controlar o efeito fixo do ano e setor na amostra do estudo; $\left({ }^{6}\right) * * *$ significante ao nível de $1 \%$; ** significante ao nível de 5\%; * significante ao nível de $10 \%$.

Quanto ao grupo com as menores firmas (empresas mais restritas), constata-se que a incerteza total, modelo (a), tem um efeito negativo e significativo sobre o nível de investimento, condizente com os estudos de Bulan (2005), para o mercado norte-americano, e o de Tran (2014), para o mercado australiano. No modelo (b), a incerteza de mercado não apresentou coeficiente significativamente diferente de zero, enquanto que a incerteza específica da firma evidenciou um coeficiente significativo em termos estatísticos ao nível de significância de 5\%. Esses achados estão condizentes com o estudo de Bulan (2005), para as empresas norteamericanas. Por fim, o modelo (c) obteve um efeito negativo e significativo da incerteza específica da firma sobre os investimentos, conforme os resultados obtidos por Bulan (2005). Em relação ao $\mathrm{R}^{2}$, observa-se um poder explicativo médio de 0,5858 , superior ao poder explicativo médio da equação geral. 
Polyandra Zampiere Pessoa da Silva - Márcio André Veras Machado

Resumidamente, verifica-se, que as firmas menores são mais sensíveis à incerteza, mudanças no ambiente de negócio, do que as firmas maiores, o que significa que a incerteza desempenha um papel ainda mais importante nas decisões de investimento de empresas financeiramente restritas, em comparação com empresas irrestritas. Ademais, nota-se que a magnitude do efeito da incerteza especifica no nível de investimento também apresentou resultados superiores ao da incerteza total, demonstrando a relevância desta variável na elaboração das políticas de investimentos das organizações. Os achadoscorroboram os estudos de Panousi e Papanikolaou (2012), para empresas norte-americanas, e Tran (2014), para empresas australianas, e contrariam os de Bulan (2005), para o mercado norte-americano. Por fim, destaca-se que as disparidade entre os coeficientes de determinação entre os grupos de firmas, maiores e menores, pode ser justificada pelo fato de que, para firmas maiores, grande parte das variáveis não apresentou p-valor significativo estatisticamente, portanto, o poder explicativo do modelo é inferior.

\subsubsection{Efeito da competitividade}

Conforme a TOR, a concorrência entre as empresas pode inibir a opção de adiar um investimento, uma vez que as organizações, para não perderem a competitividade dentro do mercado e, consequentemente, os fluxos de caixa futuros de investimento, podem adiantar a opção de investir (TRIGEORGIS, 1996; BULAN, 2005; BULAN; MAYER; SOMERVILLE, 2009; PANOUSI; PAPANIKOLAOU, 2012; CZARNITZKI; TOOLE, 2013). Nesse sentido, espera-se que as empresas mais competitivas tenham um menor impacto da incerteza sobre o nível de investimento.

Tabela 4 - Efeito da incerteza sobre o nível de investimento para as firmas mais competitivas e menos competitivas (2008-2014)

\begin{tabular}{|c|c|c|c|c|c|c|}
\hline \multirow{2}{*}{ Variáveis } & \multicolumn{3}{|c|}{ Mais competitiva } & \multicolumn{3}{|c|}{ Menos competitiva } \\
\hline & $(\mathbf{a})^{1}$ & $(b)^{1}$ & $(c)^{1}$ & $(\mathbf{a})^{1}$ & $(b)^{1}$ & $(c)^{1}$ \\
\hline QTobin & $0,0010 * * *$ & $0,0011 * * *$ & $0,0011 * * *$ & $0,0004 * * *$ & $0,0004 * * *$ & $0,0004 * * *$ \\
\hline RGI & $-0,0003$ & $-0,0003$ & $-0,0003^{*}$ & $-0,0002 * * *$ & $-0,0002 * * *$ & $-0,002 * * *$ \\
\hline RMC & $0,0007 * * *$ & $0,0007 * * *$ & $0,0007 * * *$ & $0,0026 * *$ & $0,0024 * *$ & 0,0025 \\
\hline END & $0,0476 * * *$ & $0,0483 * * *$ & $0,0484 * * *$ & $-0,0114 * * *$ & $-0,0107 * * *$ & $-0,0148 * * *$ \\
\hline INC_Total & $-0,2701 * *$ & - & - & $-0,1701$ & - & - \\
\hline INC_Mer & - & 0,0695 & $-0,1215$ & - & 0,8971 & 0,7627 \\
\hline INC_Setor & - & - & $-0,1680$ & - & - & 0,0829 \\
\hline INC_Esp & - & $-0,5508 * * *$ & $-0,5674 * * *$ & - & $-0,3745$ & $-0,1887$ \\
\hline Intercepto & $1,0518 * * *$ & $1,1805 * * *$ & $1,2235 * * *$ & $1,0550 * * *$ & 1,0601 & $1,0170 * * *$ \\
\hline $\mathbf{R}^{2}$ & 0,5717 & 0,5732 & 0,5742 & 0,2101 & 0,2170 & 0,2108 \\
\hline Teste F & $\begin{array}{l}51,08 \\
0,0000\end{array}$ & $\begin{array}{l}56,93 \\
0,0000\end{array}$ & $\begin{array}{l}52,55 \\
00000\end{array}$ & $\begin{array}{c}7,84 \\
00000\end{array}$ & $\begin{array}{c}7,49 \\
0,0000\end{array}$ & $\begin{array}{c}7,01 \\
0,0000\end{array}$ \\
\hline T. Jarque-Bera & 0,0000 & 0,0000 & 0,0000 & 0,0000 & 0,0000 & 0,0000 \\
\hline T. White & 0,0000 & 0,0000 & 0,0000 & 0,0000 & 0,0000 & 0,0000 \\
\hline T. Wooldridge & 0,0000 & 0,0000 & 0,0000 & 0,0110 & 0,0110 & 0,0110 \\
\hline Observações & 590 & 590 & 590 & 688 & 688 & 688 \\
\hline
\end{tabular}

Nota: ( $\left.{ }^{1}\right)$ Erros padrões estimados com correção para heterocedasticidade e correlação serial usando Newey-West com 1 lag, uma vez que a hipótese nula de variância homocedastica foi rejeitada, ao nível de $1 \%$, assim como de autocorrelação serial para todos os modelos; $\left({ }^{2}\right)$ em nenhum modelo foi encontrada multicolinearidade verificada por meio do teste VIF; $\left(^{3}\right)$ a hipótese nula do teste de Jarque-Bera foi rejeitada, contudo, baseando no teorema do limite central e considerando que foram utilizadas 640 e 638 observações, o pressuposto foi relaxado (BROOKS, 2008); $\left(^{3}\right)$ foram usadas dummies para setor e ano em todos os modelos, visando controlar o efeito fixo do ano e setor na amostra do estudo; $\left({ }^{4}\right) * * *$ significante ao nível de $1 \%$; ** significante ao nível de 5\%; * significante ao nível de $10 \%$. 
Para tanto, a amostra do estudo foi segregada entre empresas mais competitivas e menos competitivas. Para tanto, foi utilizada como proxy para competitividade o índice de HerfindahlHirschman (HHI), conforme Panousi e Papanikolaou (2012) e Czarnitzki e Toole (2013). A segregação das firmas como mais competitivas e menos competitivas foi feita com base na mediana do índice, isto é, as empresas com valor igual ou superior à mediana de HHI para a amostra foram classificadas como menos competitivas, pois são organizações mais concentradas, enquanto que as empresas com HHI inferior à mediana como menos competitivas.

Assim, na Tabela 4, são apresentados o efeito da incerteza sobre o nível de investimento para cada grupo de empresas (mais competitivas e menos competitivas) com diferentes proxies para incerteza.

Logo, observa-se, que para as empresas mais competitivas, a incerteza total tem um efeito negativo e significativo, conforme modelo (a). Contudo, quando à incerteza total é decomposta em seus componentes de mercado e específico da firma, com a restrição $\gamma \_i t=0$ imposta na Equação 2, modelo (b), verifica-se que apenas a incerteza específica apresenta significância estatística, especificamente, um efeito negativo. Por fim, quanto ao modelo (c), nota-se que a incerteza de mercado e do setor não apresentaram resultados diferentes de zero, enquanto que a incerteza específica tem um efeito negativo e significativo a $1 \%$ sobre o nível de investimento. Esses resultados contrariam os achados de Bulan (2005), para o mercado norte-americano, uma vez que não foi obtida significância estatística para as medidas de incerteza. Contudo, estão condizentes com os resultados encontrados nesta pesquisa para a amostra completa, conforme Tabela 2.

No que concerne às empresas menos competitivas, verifica-se que, para nenhum dos três modelos, a incerteza teve um efeito significativo estatisticamente sobre o nível de investimento. Esses resultados contrariam os encontrados por Bulan (2005), que obteve resultados inversos, isto é, efeito significativo para empresas menos competitivas e não significativo para empresas mais competitivas, assim como a TOR, uma vez que era esperado que as empresas mais competitivas sofressem um menor impacto da incerteza, quando comparadas com as empresas menos competitivas.

No entanto, destaca-se que esses resultados divergentes com o estudo de Bulan (2005) podem ter sido causados pela proxy utilizada para competitividade, uma vez que a classificação quanto ao nível de competitividade é feita por setor e não por empresa individualmente, como no caso do estudo de Bulan (2005). Outras proxies para competitividade não foram utilizadas devido à escassez de informações para o mercado brasileiro. Adicionalmente, o fato de as empresas mais competitivas terem um maior impacto da incerteza pode ser justificado como uma particularidade do mercado brasileiro; os os gestores, devido à menor concentração do mercado e, consequentemente, maior competitividade, assim como, à concentração de propriedade familiar, podem evitar assumir grandes riscos em relação ao fluxo de caixa futuro de novos investimentos.

\subsubsection{Medida alternativa de incerteza}

Para explorar a robustez dos resultados empíricos, utilizou-se uma proxy alternativa para a incerteza (INC_TA). Assim, a incerteza total da firma foi calculada pelo desvio padrão condicional do retorno das ações, conforme os estudos de Baum, Caglayan e Talavera (2008, 2010) e Tran (2014). A variância condicional do índice foi estimada pelo modelo Generalized Autoregressive Conditional Heteroskedasticity (GARCH), empresa a empresa, ano a ano. Posteriormente, calculou-se o desvio padrão condicional, isto é, a raiz quadrada da variância condicional.

Destaca-se que foram utilizados o Critério de Informação Bayesiano (BIC) e o Critério de Informação de Akaike (AIC), para verificar o melhor ajuste do modelo GARCH. Nesse 
Polyandra Zampiere Pessoa da Silva - Márcio André Veras Machado

sentido, foram escolhidos os que apresentaram menor BIC/AIC. Essa medida de incerteza total foi utilizada para o período de 2008 a 2014, assim como para o período de full IFRS. Contudo, antes de efetuar as regressões, utilizando a medida alternativa de incerteza, verificou-se se a medida alternativa de incerteza total (INC_TA) era endógena, conforme sugere o estudo de Bulan (2005) e qual melhor tipo de painel que se adéqua as observações do estudo.

Para verificação da endogeneidade, foram utilizados como instrumentos: a medida de incertezas total e específica da firma do primeiro modelo, para o período de 2008-2014, e para o período de Full IFRS a incerteza total do primeiro modelo e o $q$ de Tobin defasado. Desta forma, observou-se que INC_TA é endógena, logo, os parâmetros da Equação 4 foram regredidos pelo método de Mínimos Quadrados em Dois Estágios (MQ2E), uma vez que regredir por MQO apresentaria resultados enviesados e inconsistentes. Quanto ao tipo de painel, o mais adequado, conforme testes específicos, foi o painel do tipo pooled.

Dessa forma, conforme Tabela 5, contata-se que, para período de 2008-2014, a incerteza total teve um efeito negativo e significativo estatisticamente sobre o nível de investimento das empresas, isto é, um aumento de $1 \%$ da incerteza total da firma diminui o nível de investimento em 10,66\%. Esses resultados são condizentes com os achados de Tran (2014) para empresas australianas. Além disso, também são condizentes com a TOR, uma vez que, em elevados níveis de incerteza, os administradores têm a opção de adiar um projeto de investimento, a fim de obter mais informações sobre o investimento.

No que concerne ao período de full IFRS, observa-se que não houve variação "significativa" dos achados para o período de 2008 a 2014 com a proxy alternativa. No entanto, nota-se que o poder explicado da regressão aumentou, assim como o coeficiente da incerteza total, que passou de $-10,66 \%$ para $-12,99 \%$. Destaca-se que não foi feita a decomposição da incerteza total em seus componentes de risco de mercado, idiossincrático e específico da firma, uma vez que não foram encontrados instrumentos válidos para verificação de uma possível endogeneidade.

Tabela 5 - Efeito da incerteza sobre o nível de investimento com medida alternativa de incerteza para o período de 2008-2014 e de full IFRS

\begin{tabular}{|c|c|c|}
\hline Variáveis & $2008-2014^{1}$ & Full IFRS1 \\
\hline QTobin & $0,0005 * * *$ & $0,0006 * * *$ \\
\hline RGI & $-0,0002 * * *$ & $-0,0002 * * *$ \\
\hline RMC & $0,0007 * * *$ & $0,0007 * * *$ \\
\hline END & $0,0456 * * *$ & $0,0704 * * *$ \\
\hline INC_TA & $-10,665 * *$ & $-12,9889 * *$ \\
\hline Intercepto & $1,4447 * * *$ & $1,4447 * * *$ \\
\hline $\mathbf{R}^{2}$ & 0,3291 & 0,4856 \\
\hline Teste Wald & $8.956,79$ & 0,0000 \\
\hline$(p$-valor) & 0,0000 & 0,0000 \\
\hline T. Jarque-Bera & 0,0000 & 0,0000 \\
\hline T. White & 0,0000 & 0,0000 \\
\hline T. Wooldridge & 0,0000 & 0,0000 \\
\hline Observações & 1.278 & 942 \\
\hline
\end{tabular}

Nota: (1) Erros padrões estimados com correção para heterocedasticidade e correlação serial usando Clusterizada Robusta para Empresa de Petersen (2009), tendo em vista que a hipótese nula de variância homocedastica foi rejeitada, ao nível de 1\%, assim como de autocorrelação serial para todos os modelos; $\left({ }^{2}\right)$ em nenhum modelo foi encontrada multicolinearidade verificada por meio do teste VIF; $\left({ }^{3}\right)$ a hipótese nula do teste de Jarque-Bera foi rejeitada, contudo, baseando no teorema do limite central e considerando que foram utilizadas 1.278 e 942 observações, o pressuposto foi relaxado (BROOKS, 2008); $\left({ }^{4}\right)$ foram usadas dummies para setor e ano em todos os modelos, visando controlar o efeito fixo do ano e setor na amostra do estudo; $\left({ }^{5}\right)^{* * *}$ significante ao nível de $1 \%$; ** significante ao nível de 5\%; * significante ao nível de $10 \%$. 
INCERTEZA E INVESTIMENTO: UMA ABORDAGEM SOB A ÓTICA DA TEORIA DAS OPÇÕES REAIS

Em relação às demais variáveis explicativas, nota-se que, em ambos os períodos, os resultados foram muito semelhantes aos resultados da Tabelas 1, inclusive o sinal encontrado, com destaque para as variáveis RGI e END, que, assim como para a Tabela 1, não apresentaram o sinal esperado na literatura. Uma possível justificativa para essas particularidades foi explicada na seção 4.2. Diante do exposto, observou-se que, mesmo utilizando uma variável alternativa para incerteza total, os resultados encontrados foram semelhantes ao da primeira medida de incerteza utilizada, indicando que os gestores também devem focar na incerteza total no processo de tomada de decisão sobre investimento.

\section{CONCLUSÃO}

O presente trabalho teve como objetivo analisar o efeito da incerteza sobre o nível de investimento das empresas de capital aberto listadas na B3. Para tanto, utilizou-se como medida de incerteza a volatilidade histórica do retorno das ações, segundo os estudos de Bulan (2005), Bloom, Bond e Reenen (2007), Baum, Caglayan e Talavera (2008, 2010), Xu, Wang e Xin, (2010), Panousi e Papanikolaou (2012) e Tran (2014). Destaca-se que essa medida de incerteza total foi decomposta em seus componentes de risco (risco de mercado, risco idiossincrático e risco específico da firma). Além disso, uma medida alternativa de incerteza total foi utilizada, sendo calculada pelo desvio padrão condicional do retorno das ações por meio do modelo GARCH, conforme os estudos de Baum, Caglayan e Talavera (2008, 2010) e Tran (2014).

Assim, conforme os resultados obtidos, observou-se que a maioria das variáveis de incerteza utilizadas no estudo apresentaram poder explicativo quanto ao nível de investimento das organizações. Especificamente, as incertezas, total e específica da firma, tiveram um efeito negativo e significativo estatisticamente sobre o nível de investimento, sendo o efeito da incerteza específica superior ao da incerteza total. Diante dessas evidências, as hipóteses 2 e $2 b$, de que as incertezas total e específica da firma explicam parte das variações do nível de investimento no mercado brasileiro, não podem ser rejeitadas. Quanto à incerteza de mercado e a do setor, verificou-se que não apresentaram resultados estatisticamente significativos, portanto, as hipóteses 1 e $2 \mathrm{a}$, de que as incertezas de mercado e do setor explicam parte das variações do nível de investimento no mercado brasileiro, foram rejeitadas.

Esses resultados comprovam que o efeito da incerteza sobre o nível de investimento das empresas é explicado pela TOR, uma vez que as incertezas que impactam o nível de investimento são as incertezas, total e a específica da firma, conforme previsto pela TOR. Quanto ao período de full IFRS, observou-se que os resultados encontrados foram semelhantes aos obtidos para o período de 2008 a 2014. No entanto, o coeficiente de determinação apresentou um melhor poder explicativo, passando, em média, de 0,3579 para 0,5413.

Adicionalmente, verificou-se que as empresas menores são mais sensíveis à incerteza, mudança do ambiente de negócio, do que as empresas maiores. Especificamente, as empresas maiores só sofreram impacto da incerteza específica da firma, ao nível de $10 \%$, enquanto que as empresas menores tiveram impacto das incertezas total e específica do setor, ao nível de $5 \%$. Esses resultados podem ser explicados devido às restrições financeiras que influenciam na viabilidade de novos investimentos, uma vez que as empresas menores têm maior restrição financeira, quando comparadas às maiores. Logo, conclui-se que a incerteza desempenha um papel ainda mais importante nas decisões de investimento de empresas financeiramente restritas.

Além disso, constatou-se que as empresas mais competitivas sofrem um maior impacto da incerteza sobre o nível de investimento, quando comparadas às menos competitivas. As empresas mais competitivas tiveram impacto das incertezas, total e específica, ao nível de $1 \%$, enquanto que as menos competitivas não obtiveram impacto estatisticamente significativo de qualquer dos tipos de incerteza. Os resultados obtidos contrariam o esperado, uma vez que, conforme a TOR, a concorrência deveria inibir a opção de adiar um investimento. Contudo, o 
Polyandra Zampiere Pessoa da Silva - Márcio André Veras Machado

fato de as empresas mais competitivas terem um maior impacto na incerteza pode ser justificado como uma particularidade do mercado brasileiro; os investidores podem evitar assumir grandes riscos, para não terem prejuízo em novos investimentos, mesmo que para isso percam mercado.

Por fim, quanto à proxy alternativa de incerteza, verificou-se que os resultados não apresentaram divergências em relação à medida de incerteza calculada pela volatilidade histórica. Dessa forma, de acordo com os resultados obtidos, verifica-se que existem evidências de que as incertezas, total e específica da firma, têm um efeito negativo sobre o nível de investimento das organizações no mercado brasileiro, sendo a magnitude do efeito da incerteza da firma mais forte, quando comparado ao da incerteza total.

Os resultados da pesquisa trazem importantes implicações às finanças corporativas, quanto da determinação da taxa de desconto e das técnicas de análise de investimento, ao se avaliar a viabilidade de novos projetos. Os modelos tradicionais de análise não consideram a incerteza e a flexibilidade gerencial do ambiente empresarial. Nessa ótica, o presente estudo demonstra que a incerteza não pode ser negligenciada na análise de projetos, tendo em vista os resultados encontrados quanto a magnitude do efeito da incerteza total e especifica no nível de investimento. Sendo assim, sugere-se o uso de metodologias que capturem a incerteza e a flexibilidade empresarial, como a teoria das opções reais. Ademais, ressalta-se que pesquisas nessa área são bastante incipientes no Brasil. Portanto, o estudo traz a contribuição de debater o efeito de diferentes tipos de incerteza sobre o nível de investimento, com destaque para a abordagem das opções reaisPara futuras abordagens sobre a temática, sugere-se uma discussão a respeito do impacto da característica de propriedade das firmas na relação investimento e incerteza, tendo em vista que empresas de controle familiar podem apresentar comportamento mais conservador quando comparado a gestores de mercado (não familiar).

\section{REFERÊNCIAS}

BARBOSA FILHO, F. de H.. A crise econômica de 2014/2017. Estudos Avançados, v.31, n. 89, p. 51-60, 2017.

BAUM, C. F.; CAGLAYAN, M.; TALAVERA, O. Uncertainty determinants of firm investment. Economics Letters, v. 98, n. 3, p. 282-287, 2008.

BAUM, C. F.; CAGLAYAN, M.; TALAVERA, O. On the sensitivity of firms' investment to cash flow and uncertainty. Oxford Economic Papers-New Series, v. 62, n. 2, p.286-306, 2010 .

BEKOE, W.; ADOM, P. K. Macroeconomic Uncertainty and Private Investment in Ghana: An Empirical Investigation. International Journal of Economics and Financial Issues, v. 3, n. 2, p. 276, 2013.

BLOOM, N.; BOND, S.; REENEN, J. Uncertainty and investment dynamics. The review of economic studies, v. 74, n. 2, p. 391-415, 2007.

BORÇA JUNIOR, G. R.; TORRES FILHO, E. T. Analisando a crise do subprime. Revista do BNDES, Rio de Janeiro, v.15, n.30 , p. 129-159, dez. 2008.

BROOKS, C. Introductory econometrics for finance. Cambridge university press, 2008. 
INCERTEZA E INVESTIMENTO: UMA ABORDAGEM SOB A ÓTICA DA TEORIA DAS OPÇÕES REAIS

BULAN, L. T. Firm investment behavior in a real options framework: empirical

evidence. 2001. 128f. Thesis (Doctor of Philosophy) - Graduate School of Arts and Science, Columbia University, Columbia.

BULAN, L. T. Real options, irreversible investment and firm uncertainty: New evidence from US firms. Review of Financial Economics, v. 14, n. 3, p. 255-279, 2005.

BULAN, L.; MAYER, C.; SOMERVILLE, C. T. Irreversible investment, real options, and competition: Evidence from real estate development. Journal of Urban Economics, v. 65, n. 3, p. 237-251, 2009.

CZARNITZKI, Dirk; TOOLE, Andrew A. The R\&D Investment-Uncertainty Relationship: Do Strategic Rivalry and Firm Size Matter?. Managerial and Decision Economics, v. 34, n. 1, p. 15-28, 2013.

DIXIT, A. K.; PINDYCK, R. S. Investment under uncertainty. Princeton, New Jersey: Princeton University Press, 1994.

ESCALERAS, M.; KOTTARIDI, C. The joint effect of macroeconomic uncertainty, sociopolitical instability, and public provision on private investment. The Journal of Developing Areas, v. 48, n. 1, p. 227-251, 2014.

FAMA, E. F.; FRENCH, K. R. The cross-section of expected stock returns. Journal of Finance, v. 47, n. 2, p. 427-465, 1992.

HAYASHI, F. Tobin's marginal q and average q: A neoclassical interpretation.

Econometrica: Journal of the Econometric Society, v. 50, n. 1, p. 213-224, 1982.

MACHADO, M. A. V. ; FAFF, R. W. Crescimento de ativos e retorno de ações: evidências no mercado brasileiro. Rev. contab. finanç., São Paulo , v. 29, n. 78, p. 418-434, 2018

MINARDI, A. M. A. F. Teoria de opções aplicada a projetos de investimento. Revista de Administração de Empresas (RAE), v. 40, n. 2, p. 74-79, 2000.

MODIGLIANI, F.; MILLER, M. H. The cost of capital, corporation finance and the theory of investment. The American Economic Review, v. 48, n. 3, p. 261-297, 1958.

MYERS, S. C. The capital structure puzzle. The journal of finance, v. 39, n. 3, p. 574-592, 1984.

PANOUSI, V.; PAPANIKOLAOU, D. Investment, idiosyncratic risk, and ownership. The Journal of Finance, v. 67, n. 3, p. 1113-1148, 2012.

SÂMAN, C. Macroeconomic uncertainty and investment: empirical analysis for Romania. Romanian Journal of Economic Forecasting, v. 2, p. 155-164, 2010.

TOBIN, J. A general equilibrium approach to monetary theory. Journal of Money, Credit and Banking, v. 1, n. 1, p. 15-29, 1969. 
Polyandra Zampiere Pessoa da Silva - Márcio André Veras Machado

TRAN, T. L. Uncertainty and investment: evidence from Australian firm panel data.

Economic Record, v. 90, n. s1, p. 87-101, 2014.

TRIGEORGIS, L. Real options: Managerial flexibility and strategy in resource allocation. Cambridge/Massachusetts: The MIT Pres, 1996.

XU, L.; WANG, J.; XIN, Y. Government control, uncertainty, and investment decisions in China's listed companies. China Journal of Accounting Research, v. 3, n. 1, p. 131-157, 2010. 